\title{
EXPERIMENTAL INVESTIGATION ON ELEVATED WATER TANKS WITH BASE ISOLATION - RESPONSE SPECTRUM APPROACH
}

\author{
Paul P.A. Vimal, Joseph D.J. Regin \\ St. Xavier's Catholic College of Engineering, Department of Civil Engineering, Tamil Nadu, India \\ e-mail: antonyvimal4165@gmail.com; jerlin_regin2003@yahoo.com
}

Gowthami T.R. JinU

University College of Engineering Nagercoil, Department of Mechanical Engineering, Tamil Nadu, India e-mail: grjinu1980@gmail.com

Chembakaraman G. Chettiar

St. Xavier's Catholic College of Engineering, Department of Civil Engineering, Tamil Nadu, India e-mail: ganapathy2504@gmail.com

\begin{abstract}
Elevated water tanks in an empty condition, though not important in structural design, becomes an important problem in seismic design. The objective of the present research is to investigate the elevated water tanks in empty and in filled conditions and to emphasize the importance of seismic response. Four elevated tanks with various parameters are selected for seismic analysis with the base isolation technique. It is found out that empty tanks are highly vulnerable to earthquake effects, whereas filled tanks can be mitigated by providing base isolation. A simple experimental investigation has also been carried out to validate the analytical results.
\end{abstract}

Keywords: response spectrum, base isolation, natural time period, base shear, spectral acceleration

\section{Introduction}

Earthquake occurrence in Bhuj, Gujarat, India, on 26th January of 2001 left the entire country in scare. The death toll and fatalities were immeasurable. Since then, researchers started realizing that the scale of catastrophe could be reduced to a great extent if the buildings were constructed as earthquake resistant. Indian code, namely (IS1893(Part 1):2002) gives the specifications to be followed for designing earthquake-resistant buildings.

Generally, there are two types of methods in making the building earthquake resistant, called conventional and nonconventional methods. A conventional method is the traditional one which consists in resisting lateral force by increasing design capacity and stiffness. A nonconventional method deals with reducing the seismic demand instead of increasing strength by providing either base isolation devices or dampers (Agarwal and Shrikhande, 2013; Mirza Hessabi et al., 2017).

Shekari et al. (2010) investigated seismic performances of elevated water tanks subjected to long period ground shaking. The effectiveness of the base isolation system on tanks of various aspect ratio was tested, and it was concluded that seismic responses of slender and wide liquid storage tanks could be reduced considerably by installing base isolation systems.

Seleemah and El-Sharkawy (2011) observed that 50\%-90\% of base shear as well as impulsive displacement get reduced when the liquid storage tanks were provided with a base isolation system. Three kinds of isolation systems were considered and the results were compared with 
fixed based tanks. It was also concluded that the effect of base isolation is significant in slender tanks when compared to broad tanks.

Shrimali and Jangid (2004) carried out analytical studies for determining seismic responses of base isolated ground supported tanks. Seismic analysis of tanks with different aspect ratio were done using three methods such as modal superposition method, response spectrum method and an approximate method. Finally, it was concluded that the simplified approximate method was found to match with other two methods.

Wang et al. (2001) assessed the possibility of increasing the earthquake resistance of rigid cylindrical tanks by providing base isolation devices. Friction pendulum seismic bearings were adopted. A hydrodynamic model was developed to determine the seismic responses more efficiently. The extensive research confirmed the effectiveness of the base isolation system of friction pendulum seismic bearings.

Kanyilmaz and Castiglioni (2017) found that the existing silos, which were designed before the latest revision of earthquake code books, are highly susceptible to earthquakes. The existing structures were retrofitted by base isolation devices in the form of curved surface single sliding pendulum devices. The reduction in seismic responses of the retrofitted structures were compared with original structures.

Ghateh et al. (2015) developed an approach to establish seismic response factors for tanks ranging from small to very big in size. Pushover curves were drawn for forty-eight prototypes selected, and the seismic response factors were determined from those curves. Out of the various factors considered, it was found out that the tank size is the main factor affecting the seismic response factors of tanks. Finally, it was concluded that the same response factors should not be used for all types of tanks. Instead, it had to be used according to the tank size.

Hirde et al. (2011) emphasized the importance of elevated water tanks in the seismic prone region especially after the occurrence of an earthquake. Seismic performances of 240 models of elevated water tanks were studied by varying different parameters such as height of tanks, soil conditions and seismic zones. Belostotskiy et al. (2015) did a numerical simulation of partially filled thin cylindrical tanks considering the sloshing effects for both linear and nonlinear conditions. In addition to the fluid-structure interaction, partitioned and simultaneous solution procedures were investigated. Finally, the results obtained from the software were discussed with the codal provisions.

Chaduvula et al. (2013) considered the fluid- soil-structure interaction effects on the seismic performance of elevated water tanks. A model of cylindrical steel tank of scale 1:4 was constructed and was subjected to acceleration along the horizontal and vertical direction along with rocking motion. It was found out that the base shear, base moment and hydrostatic pressures were increasing with the increase in acceleration, and the results obtained experimentally were compared with the results obtained using various codes.

Mori et al. (2015) did a seismic assessment of heritage-listed two elevated water tanks. One was taller with framed staging and another one shorter with shaft staging using time history analysis and suggested different retrofitting techniques for each tank. The analysis showed taller one suffered a numerical collapse of the framed structure, whereas tensile stress beyond the permissible limit took place in the large space of the shaft staging of the shorter one.

From the literature review, it is understood that researches on elevated water tanks with the filled condition were more emphasized than with the empty condition. But the empty tank of elevated water tanks becomes important in the seismic design in certain conditions. As seismic performances of empty tanks differ from those of filled tanks regarding natural time period, it is very much essential to determine their performances during an earthquake. So, this research involves giving additional importance to the performance of empty tanks. 


\section{Base isolated elevated tank}

The main function of base isolation systems is to decouple the super-structure from the sub-structure, which is mainly subjected to the excitation from earthquake energy transmitted from the epicentre. So, a certain amount of energy will be dissipated from being transmitted to the super-structure. The mass of the base slab and lateral stiffness of isolation devices are to be fixed as needed. When isolation is provided, displacement will be very high at the level of the isolation devices and the behaviour of super-structure seems to be a rigid body. But, in the case of highly elevated water tank, this rigid movement is doubtful as the mass is lumped at the top. The main intention of this research is to investigate the seismic performance of elevated water tanks with and without providing base isolation and its variation with respect to fundamental natural time period. Therefore, four different types of tanks varying with respect to the storage capacity as well as horizontal-bracing configurations have been selected. The structural frames and horizontal bracings of four elevated water tanks with fixed base are shown in Fig. 1.

(a)

Tank 1

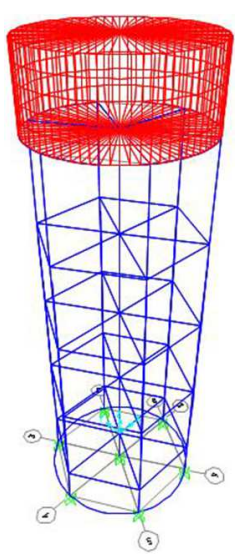

(b)

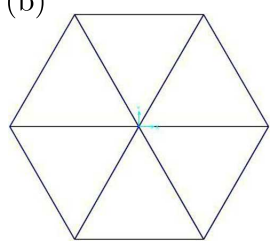

Tank 2
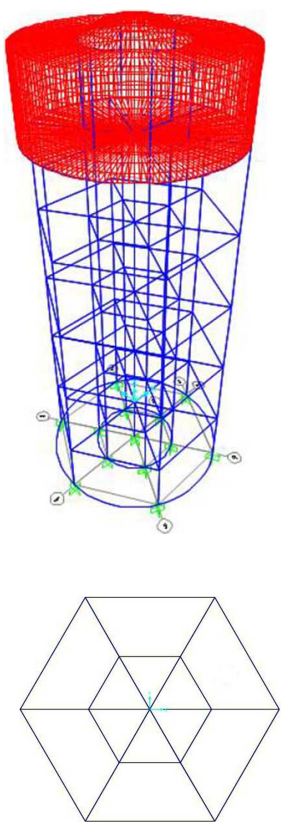

Tank 3
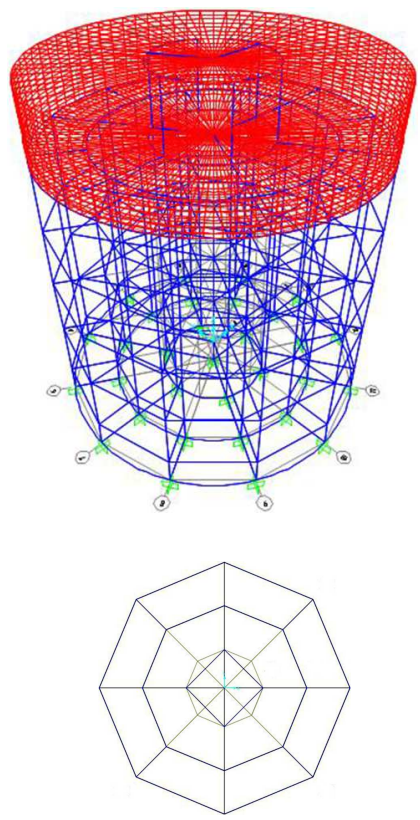

Tank 4
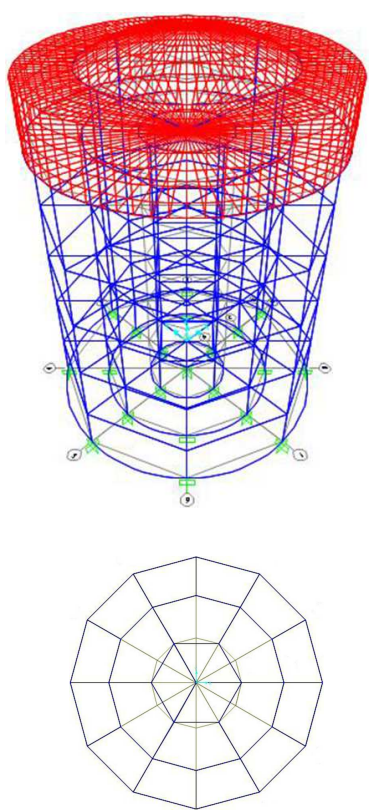

Fig. 1. Structural modeling of elevated water tanks: (a) structural configuration of elevated water tank, (b) horizontal brackins of elevated water tanks

Seismic response quantities such as roof displacement $\delta_{\text {roof }}$, base shear $V$ and base moment $M$ have been calculated for those elevated water tanks. When the tanks are provided with base isolation, their degree of freedom will be increased by one. Staad-pro software is used to calculate the lateral stiffness of elevated water tanks. If the tank is completely or partially filled with water, it is treated as a two degrees of freedom system (impulsive mode and convective mode) and if it is an empty tank, it is considered as a single degree of freedom system. It is depicted in Fig. 2. Natural time periods for both kinds of tanks are calculated as per guidelines (IITK-GSDMA, 2007 and Housner, 1963) and for these natural time periods, pseudo spectral accelerations $\left(S_{a} / g\right)$ have been obtained from the elastic design response spectrum.

When elevated water tanks are provided with the base isolation system, their degree of freedom is increased by one, i.e., degree of freedom of an empty tank and the tank filled with water with base isolation are two and three, respectively. Generally, the force displacement relationship of isolation systems is nonlinear in nature. But only linear behaviour is considered 
(a)

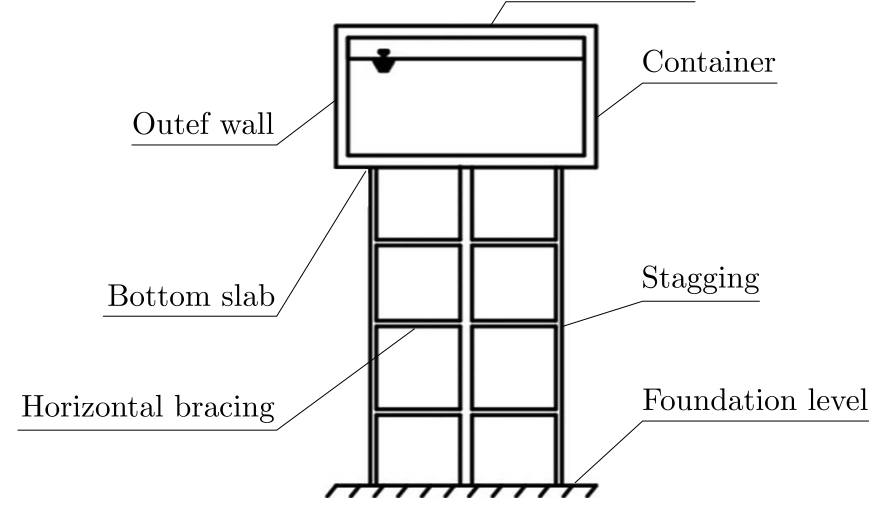

(b)

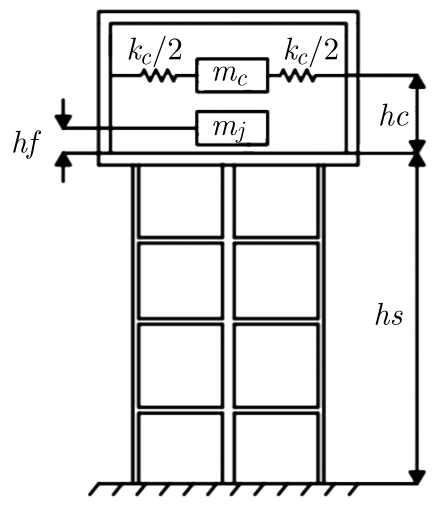

(c)

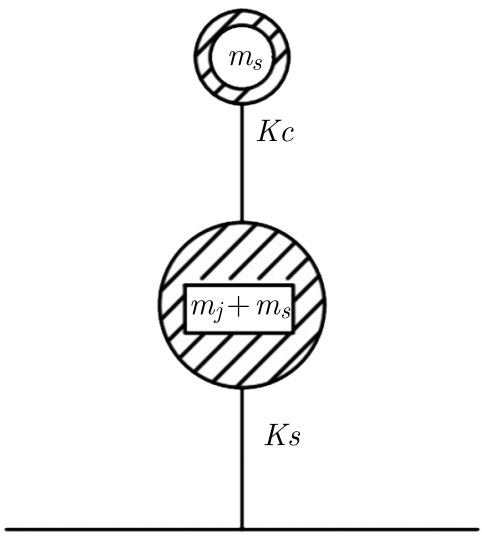

(d)

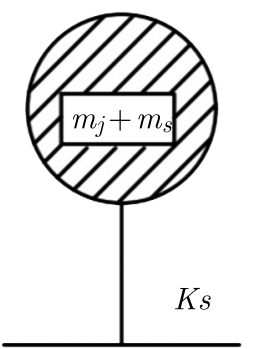

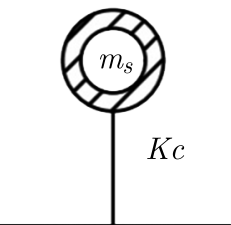

Fig. 2. Structural idealization of an elevated water filled tank without base isolation: (a) over head water tank, (b) spring mass model, (c) two mass idealization of the over head water tank, (d) equivalent two number of the uncoupled system

here in order to emphasise the effectiveness of the base isolation system. Dynamic properties such as the fundamental natural frequency, its corresponding natural time period and damping ratio of the tank with a fixed base are represented by $\omega_{f}, T_{f}$ and $\zeta_{f}$, respectively. Meanwhile, the subscript term $f$ is replaced by $b$ for the tank resting on the base isolation system. The basic equation of motion for a multiple degrees of freedom system (Chopra, 2012; Clough and Penzien, 1993) is given as

$$
\mathbf{M} \ddot{\mathbf{x}}+\mathbf{C} \dot{\mathbf{x}}+\mathbf{K x}=-\mathbf{M} \ddot{\mathbf{x}}_{g}(t)
$$

where $\mathbf{M}$ - mass matrix, $\mathbf{C}$ - damping matrix, $\mathbf{K}$ - stiffness matrix, $\mathbf{x}$ - structural displacement response, $\dot{\mathbf{x}}$ - structural velocity response, $\ddot{\mathbf{x}}-$ structural acceleration response, $\ddot{\mathbf{x}}_{g}$ - ground acceleration due to an earthquake.

The elevated water tank without water resting on the base isolation system is to be treated as a two degrees of freedom system and its stiffness, mass and damping matrices are denoted by $\mathbf{K}, \mathbf{M}, \mathbf{C}$, respectively. Generally, there is a huge deviation between high damping of the isolation system with rubber bearings and low damping of the super-structures. Therefore, the damping coefficient matrix of the combined system is nonclassical. Normally, in modal analysis, the coupled equations are converted into uncoupled equations and split into $N$ single degrees of freedom systems where $N$ is the number of degrees of freedom. But it is impractical to adopt modal analysis for the nonclassically damped systems (Paz and Leigh, 2010). But this research is mainly intended to determine the dynamic response of a tank resting on both the fixed base and base isolation systems, and also to determine the effectiveness of the base isolation system. Therefore, it is reasonable to adopt modal analysis here even though it will give approximate 
results. Mass and stiffness matrices of the two degrees of freedom systems and their characteristic equations are solved in order to obtain the natural frequencies and mode shapes. Then the responses from the two uncoupled equations of motion using modal analysis are obtained by the response spectrum method. and its total response is calculated as a square root of the result from the square method.

In order to gain knowledge about the effectiveness of base isolation, four elevated water tanks with various capacity are selected. Their dynamic properties and capacity details are shown in Table 1. Weight of the container, staging, horizontal bracing and centre of gravity of the empty container are calculated, and the lateral stiffness of each tank is calculated by applying a lateral load to the top of the tank and measuring the displacement using Staad-pro software. The damping ratio of tank is adopted as $2 \%$, even though, normally it is taken as $5 \%$ for dynamic analysis of structures (Chopra, 2012).

Table 1. Geometric and structural properties of elevated water tanks

\begin{tabular}{|l|c|c|c|c|}
\hline \multicolumn{1}{|c|}{ Dynamic parameters } & Tank 1 & Tank 2 & Tank 3 & Tank 4 \\
\hline \hline Impulsive mass [kg] & 45528.02 & 94893.52 & 121889.14 & 133126.16 \\
\hline Convective mass [kg] & 55057.14 & 120570.6 & 378781.08 & 279135.50 \\
\hline Height of impulsive mass [m] & 2.7 & 3.7718 & 8.4046 & 5.325 \\
\hline Height of convective mass [m] & 2.625 & 3.3725 & 9.16875 & 5.325 \\
\hline $\begin{array}{l}\text { Mass of container and one third } \\
\text { mass of staging [kg] }\end{array}$ & 94468.09 & 201927.1 & 946803.33 & 358807.33 \\
\hline $\begin{array}{l}\text { Height of centre of gravity } \\
\text { from base of container [m] }\end{array}$ & 0.778 & 0.865 & 0.891 & 0.802 \\
\hline Stiffness [kN/m] & 3675.119 & 5488.47 & 28409.09 & 10905.125 \\
\hline Impulsive time period [s] & 1.226 & 1.4611 & 1.2186 & 1.3344 \\
\hline Convective time period [s] & 2.90 & 3.4245 & 5.893 & 4.287 \\
\hline Empty tank time period [s] & 1.0073 & 1.205 & 1.147 & 1.1397 \\
\hline
\end{tabular}

\subsection{Base isolation system - super-structure interaction effect}

The damping ratio of base isolation devices and that of elevated water tanks are taken as $10 \%$ and $2 \%$, respectively. As significant difference in damping of both the base isolation devices and that of the elevated water tank exists, and a classical damping matrix cannot be assumed for the combined base isolated elevated water tank. Here, the challenge is how to construct the nonclassical damping matrix for the combined system. It is done by framing the classical damping matrix for the elevated water tank alone without considering base isolation devices at first. Then energy dissipating damping contribution from the isolators is added in order to get the damping matrix of the combined system (Livaoğlu and Doğangün, 2006).

The damping matrix of fixed based tanks is obtained using the relation $C_{f}=a_{1} k_{f}$, where $a_{1}=2 \zeta_{1} / \omega_{1}$. Natural frequencies and the corresponding natural time periods of tanks are obtained using the eigenvalues and eigenvectors concept. Then, modal analysis is done to obtain the responses such as modal damping ratio, modal static responses, roof displacement, base shear and base moment on individual degree of freedom system using the response spectrum method. The elastic design response spectrum from (IS1893(Part 1):2002) is referred and then the total response is obtained by square root summation of the square method. Mode shapes of the empty tank and a tank filled with water are delineated in Figs. 3a and 3b. 
(a)

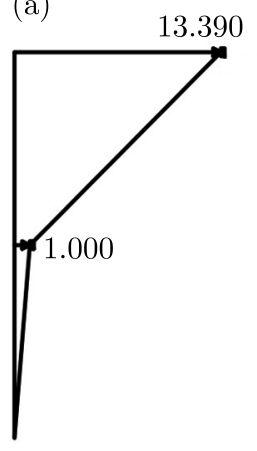

First mode

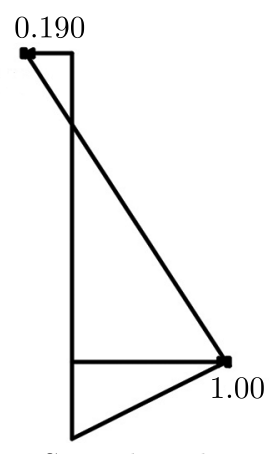

Second mode (b)

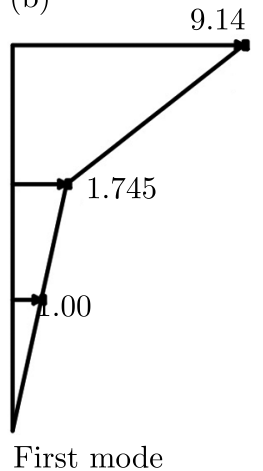

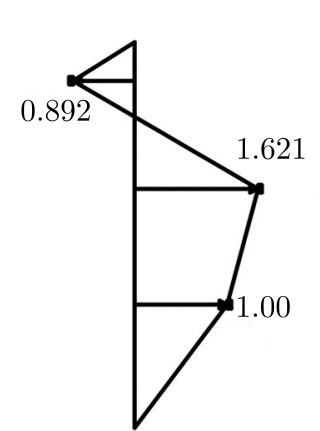

Second mode

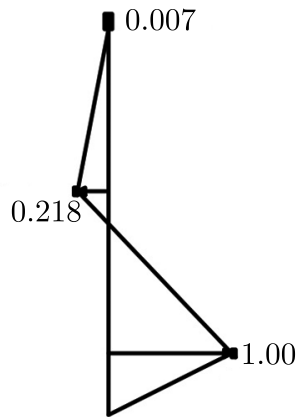

Third mode

Fig. 3. Mode shape of elevated filled water tank 1: (a) fixed based tank, (b) base isolated tank

\section{Vibration properties of base isolated tanks}

Mass of the base slab and lateral stiffness of the isolation system are represented as $m_{b}$ and $k_{b}$, respectively. Here, $m_{b}$ is taken as $2 / 3$ of mass of staging and $k_{s}=\left(M+m_{b}\right) \omega_{b}^{2}$, where $M$ is total mass of the tank. Having framed the mass matrix and stiffness matrix of the base isolated tanks, the next step is to solve the characteristic equation, as mentioned in the fixed based tanks, in order to get the natural frequencies and mode shapes. Equation (2.2) shows the characteristic equation to be solved and Eqs. (2.3) are used to calculate the dynamic properties of the fixed and isolated tanks, respectively

$$
\left|K_{f}-M_{f} \omega_{n}^{2}\right| \boldsymbol{\phi}=\mathbf{0} \quad\left|K_{b}-M_{b} \omega_{n}^{2}\right| \boldsymbol{\phi}=\mathbf{0}
$$

and

$$
\begin{array}{rlrl}
T_{f} & =\frac{2 \pi}{\omega_{f}} & T_{b}=\frac{2 \pi}{\omega_{b}} \quad \omega_{b}=\sqrt{\frac{k}{m+m_{b}}} \\
\zeta_{f}=\frac{c}{2 m \omega_{f}} & \zeta_{b}=\frac{c_{b}}{2\left(m+m_{b}\right) \omega_{b}}
\end{array}
$$

The sizes of mass and stiffness matrices and the results of vibration properties are given in Tables 2 and 3, respectively. The mode shape of tank 1 is depicted in Fig. 3. Modal static distribution of the earthquake force $S_{n}$ is calculated using Eq. (2.4), and its direction is directly proportional to mode shapes. For example, the forces of $S_{n}$ due to the first mode are positive when moving from the bottom to the top

$$
S_{n}=\Gamma_{n} m \phi_{n}
$$

where

$$
\Gamma_{n}=\frac{L_{n}^{h}}{M_{n}} \quad L_{n}^{h}=\sum_{j=1}^{n} m_{j} \phi_{j n}
$$

The modal damping ratio $\zeta$ is calculated as

$$
\zeta_{n}=\frac{C}{2 M_{n} \phi_{n}}
$$

where $C_{n}=\phi_{n}^{\mathrm{T}} C \phi_{n}$ and $M_{n}=\phi_{n}^{\mathrm{T}} M \phi_{n}$. In the case of fixed tanks, it is observed that the damping ratio is almost $2 \%$ in the first mode and varies from $5 \%$ to $10 \%$ from tank 1 to tank 4 in the second mode. Since the mammoth amount of mass is lumped in the top, the behaviour 
Table 2. Vibration properties of elevated water tanks with fixed base

\begin{tabular}{|c|c|c|c|c|c|c|c|c|c|}
\hline \multirow{3}{*}{$\begin{array}{c}\text { Tank } \\
\text { No. }\end{array}$} & \multicolumn{4}{|c|}{ Tank filled with water } & \multicolumn{3}{c|}{ Empty tank } \\
\cline { 2 - 11 } & $\begin{array}{c}|c| \\
\text { Impulsive mode } \\
{[\mathrm{rad} / \mathrm{s}]}\end{array}$ & $\begin{array}{c}f \\
{[\mathrm{~Hz}]}\end{array}$ & $\begin{array}{c}T \\
{[\mathrm{~s}]}\end{array}$ & $\begin{array}{c}\omega \\
{[\mathrm{rad} / \mathrm{s}]}\end{array}$ & $\begin{array}{c}f \\
{[\mathrm{~Hz}]}\end{array}$ & $\begin{array}{c}T \\
{[\mathrm{~s}]}\end{array}$ & $\begin{array}{c}\omega \\
{[\mathrm{rad} / \mathrm{s}]}\end{array}$ & $\begin{array}{c}f \\
{[\mathrm{~Hz}]}\end{array}$ & $\begin{array}{c}T \\
{[\mathrm{~s}]}\end{array}$ \\
\hline \hline 1 & 2.047 & 0.326 & 3.068 & 5.326 & 0.848 & 1.179 & 6.237 & 0.993 & 1.007 \\
\hline 2 & 1.761 & 0.280 & 3.566 & 4.488 & 0.715 & 1.399 & 5.213 & 0.830 & 1.205 \\
\hline 3 & 1.422 & 0.227 & 4.415 & 4.848 & 0.772 & 1.295 & 5.513 & 0.877 & 1.140 \\
\hline 4 & 1.048 & 0.167 & 5.991 & 5.196 & 0.827 & 1.209 & 5.477 & 0.871 & 1.147 \\
\hline
\end{tabular}

Table 3. Vibration properties of elevated water tanks with base isolation

\begin{tabular}{|c|c|c|c|c|c|c|c|c|c|c|c|c|c|c|c|}
\hline \multirow{3}{*}{ 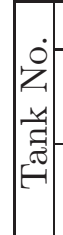 } & \multicolumn{9}{|c|}{ Tank filled with we } & \multicolumn{6}{|c|}{ Empty tank } \\
\hline & \multicolumn{3}{|c|}{$\begin{array}{c}\text { Fundamental } \\
\text { mode }\end{array}$} & \multicolumn{3}{|c|}{ 2nd mode } & \multicolumn{3}{|c|}{ 3rd mode } & \multicolumn{3}{|c|}{$\begin{array}{c}\text { Fundamental } \\
\text { mode }\end{array}$} & \multicolumn{3}{|c|}{ 2nd moc } \\
\hline & $\begin{array}{c}\omega \\
{[\mathrm{rad} / \mathrm{s}]}\end{array}$ & $\begin{array}{c}f \\
{[\mathrm{~Hz}]}\end{array}$ & \begin{tabular}{|l}
$T$ \\
{$[\mathrm{~s}]$}
\end{tabular} & $\begin{array}{l}\omega \\
a d / s]\end{array}$ & $\begin{array}{c}f \\
{[\mathrm{~Hz}]}\end{array}$ & $\begin{array}{l}T \\
{[\mathrm{~s}]}\end{array}$ & $\begin{array}{c}\omega \\
{[\mathrm{rad} / \mathrm{s}]}\end{array}$ & $\left.\begin{array}{c}f \\
{[\mathrm{~Hz}]}\end{array}\right]$ & $\begin{array}{l}T \\
{[\mathrm{~s}]}\end{array}$ & $\begin{array}{c}\omega \\
{[\mathrm{rad} / \mathrm{s}]}\end{array}$ & $\left.\begin{array}{|c|c}f \\
{[\mathrm{~Hz}]}\end{array}\right]$ & \begin{tabular}{|l}
$T$ \\
{$[\mathrm{~s}]$}
\end{tabular} & $\begin{array}{c}\omega \\
{[\mathrm{rad} / \mathrm{s}]}\end{array}$ & $\begin{array}{c}f \\
{[\mathrm{~Hz}]}\end{array}$ & $\begin{array}{l}T \\
{[\mathrm{~s}]}\end{array}$ \\
\hline & $\bar{~} 1.91$ & 0.31 & 3.28 & 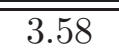 & 0.57 & 1.75 & 12.18 & 1.94 & $\overline{0.52}$ & 3.25 & 0.52 & 1.93 & 111.84 & 1.883 & 0.53 \\
\hline & 1.67 & 0.27 & 3.75 & 3.27 & 0.52 & 1.92 & 10. & \begin{tabular}{|l|}
1.72 \\
\end{tabular} & & 3.14 & 0.50 & 2.00 & 10.35 & 1.64 & \\
\hline & 1.38 & 0.22 & 4.56 & 3.37 & 0.54 & 1.86 & & 2.07 & & 3.06 & 0.49 & 2.05 & 2.14 & .945 & 0.51 \\
\hline & 1.04 & 0.17 & 6.07 & 3.22 & 0.51 & 1.95 & 13.60 & 2.16 & 0.46 & 3.01 & 0.48 & 2.09 & 13.07 & 2.079 & 0.48 \\
\hline
\end{tabular}

of the structure will not be rigid, and instead, highly deformed. This might be the reason for higher damping in the second mode. Meanwhile, damping in the 3rd mode of isolated tanks is very high ranging from $20 \%$ for tank 1 to $37 \%$ for tank 4 . This huge value is contributed by a high amount of damping present in the isolation system.

\subsection{Peak modal and total responses}

The peak value $r_{n o}$ of the responses of each mode is obtained from the elastic design response spectrum. From the elastic design response spectrum given in (IS1893(Part 1):2002) as shown in Fig. 4, it is known that the two main factors are influencing the spectral acceleration are damping ratio and natural time period. The dynamic response is directly proportional to spectral acceleration and which, in turn, depends on the natural time period. Therefore, the natural time period plays a vital role in governing the dynamic response during an earthquake. As per guidelines (IITK-GSDMA, 2007; IS1893(Part 1):2002), the importance factor $I$ is taken as 1.5, as the elevated water tank should exist even after the occurrence of earthquakes and the response reduction factor $R$ as 2.5 as it confirms ductile detailing (IS13920:1993) and special resisting frame moment. Becouse the region is of low seismic intensity, the relevant zone factor $Z$ is adopted as 0.1. Once the above values are fixed, the design seismic horizontal acceleration coefficient is calculated from

$$
A_{h}=\frac{Z}{2} \frac{I}{R} \frac{S_{a}}{g}
$$

Response quantities due to each mode is given by $r_{n}=r_{n}^{s t}\left(S_{a} / g\right)$, where $r_{n}^{s t}$ is the static response and $S_{a} / g$ is the spectral acceleration, i.e., dynamic response. Equations (2.7) are the formulae used to calculate the base shear and base moment (ACI 350.3, 2006; NZS 3106, 2009) and are static base shear and base moments due to the $n$-th mode

$$
V_{b n}=V_{b n}^{s t} A_{n} \quad M_{b n}=M_{b n}^{s t} A_{n}
$$


where

$$
M_{b n}^{s t}=M_{n}^{*} h_{n}^{*} \quad M_{n}^{*}=V_{b n}^{s t}
$$

Roof displacements of elevated tanks are calculated using

$$
\delta_{j n}=\Gamma_{n} \phi_{n} D_{n}
$$

where $D_{n}$ is the spectral displacement ordinate obtained by dividing the spectral acceleration by $\omega_{n}^{2}$.

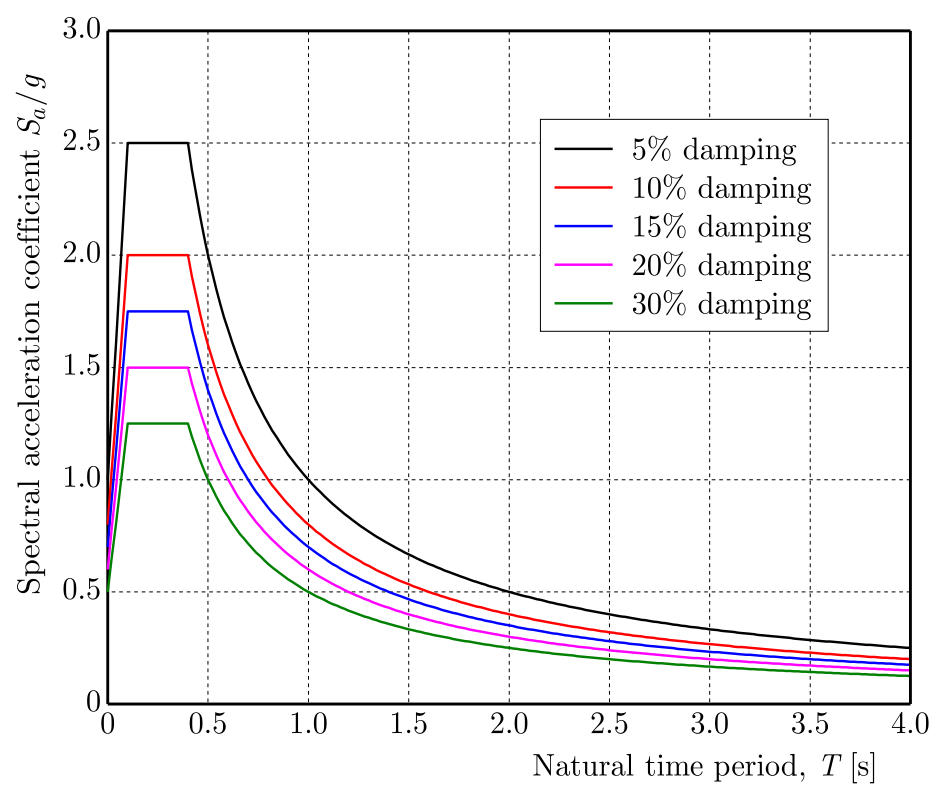

Fig. 4. Elastic design response spectrum from (IS1893(Part 1):2002)

\section{Experimental work}

\subsection{Procedure}

A tank model made of steel is resting on a steel base plate, and spring isolation is provided below the base plate. In the spring isolation system, the suspension system in the form of springs is placed between the sub-structure and super-structure. The spring isolation dissipates vibration energy induced by dynamic load and protects the super-structure. The specifications of the steel open coiled springs are as follows: inside diameter of the coil and diameter of the wire are $40 \mathrm{~mm}$ and $5 \mathrm{~mm}$, respectively. The number of turns is 8 and the slope of coil is $20^{\circ}$. The corresponding stiffness of spring is calculated to be equal to $5.804 \mathrm{kN} / \mathrm{m}$ (Mahadevan and Reddy, 2019). Harmonic forced vibration is induced at a rate of 2 cycles per second in the base plate level. An accelerometer, a device used to measure motion of a structure along three mutually perpendicular directions $x, y$ and $z$, consists of an Arduino Board with a microcontroller. It is simply connected to a computer with a USB cable for gathering accelerometer values from the roof level of the tank. The load is being applied continuously up to $15 \mathrm{~s}$ and the acceleration response is readily plotted in numerical values as well as a graphical form in the computer system. Table 4 shows the readings of roof displacement of the tanks which are obtained by doing double time integration of the acceleration values from the test conducted. Figure 5 shows details of the models of elevated tanks, the accelerometer and isolation device. Results in graphical forms are depicted in Fig. 6. The major excitations shown in the first and second row delineate the roof accelerations along $x, y$ directions, respectively, and the smallest excitation depicted in the second row represents the acceleration in the $z$ direction. 
Table 4. Results of $\delta_{\text {roof }}$ of both elevated tanks

\begin{tabular}{|c|c|c|c|c|}
\hline \multirow{2}{*}{$\begin{array}{c}\text { Tank } \\
\text { No. }\end{array}$} & \multicolumn{2}{|c|}{ Fixed base } & \multicolumn{2}{|c|}{ Isolated base } \\
\hline & $\begin{array}{l}\text { Filled tank } \\
{[\mathrm{mm}]}\end{array}$ & $\begin{array}{c}\text { Empty tank } \\
{[\mathrm{mm}]}\end{array}$ & $\begin{array}{c}\text { Filled tank } \\
{[\mathrm{mm}]}\end{array}$ & $\begin{array}{c}\text { Empty tank } \\
\text { [mm] }\end{array}$ \\
\hline 1 & 165.926 & 148.543 & 195.708 & 172.212 \\
\hline 2 & 172.249 & 121.655 & 614.969 & 579.607 \\
\hline
\end{tabular}

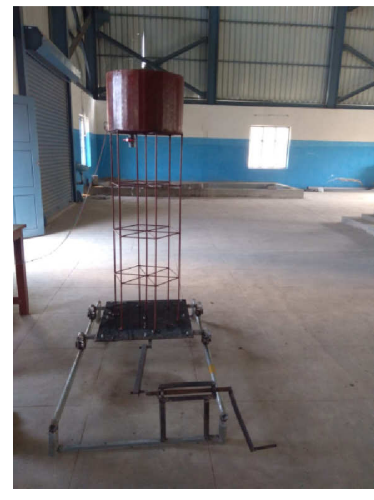

Mode 1

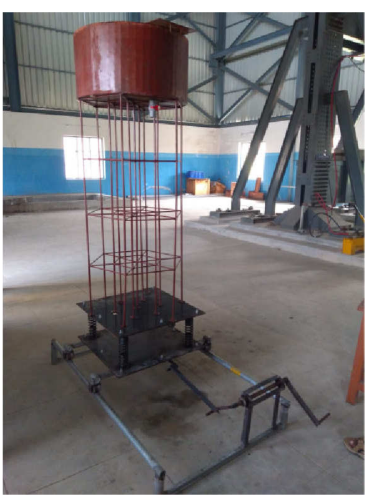

Mode 2

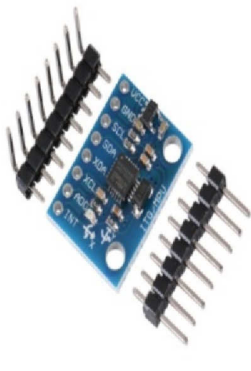

Accelerometer

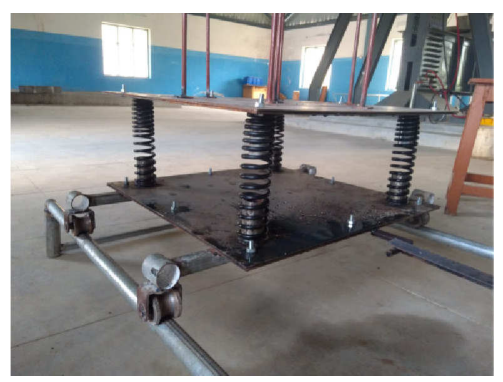

Base isolation device

Fig. 5. Experimental details of elevated water tanks: (a) model 1, (b) model 2, (c) accelerometer, (d) base isolation device

(a)

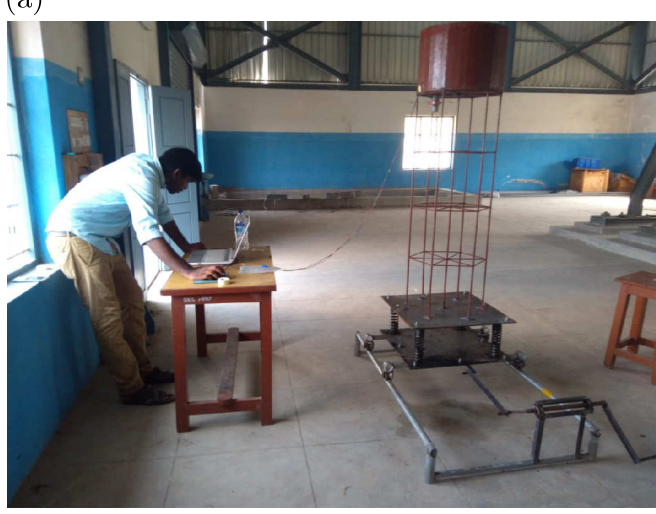

(b)

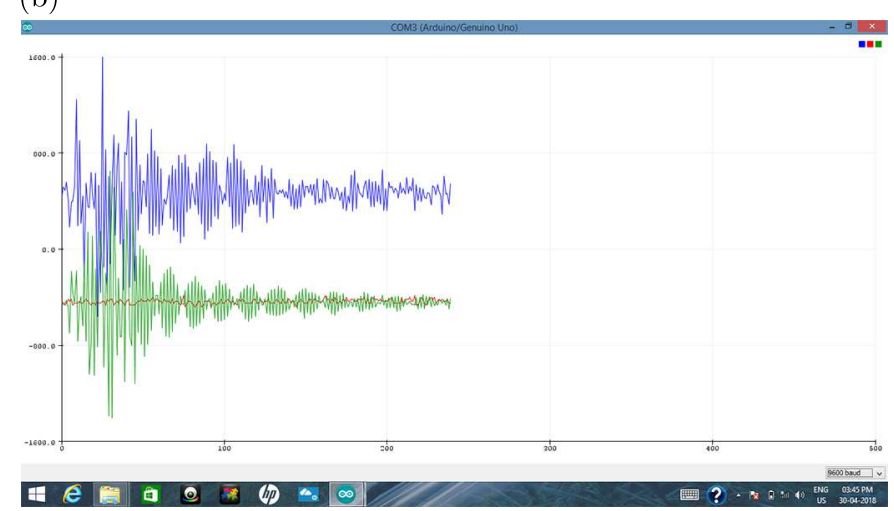

Fig. 6. Experimental details of elevated water tanks: (a) experiment on elevated water tank 1,

(b) recorded acceleration values along three directions

\section{2. $\quad$ Model detailing}

It has been decided to adopt two tanks reflecting the configurations of tank 1 and tank 2 in order to test displacements of tanks experimentally with and without providing base isolation. Heights of the staging and container were fixed at $1.6 \mathrm{~m}$ and $0.35 \mathrm{~m}$, respectively. Thicknesses of the roof slab, base slab and wall were taken as $2 \mathrm{~mm}, 3 \mathrm{~mm}$ and $2 \mathrm{~mm}$, respectively. Diameter of steel rods reflecting the columns and tie beams were adopted as $10 \mathrm{~mm}$ and $8 \mathrm{~mm}$, respectively. Differences between the tanks are the storage capacity and horizontal bracing configurations. Diameters of container of the 1st and 2nd tank were fixed at $0.45 \mathrm{~m}$ and $0.6 \mathrm{~m}$, respectively. the bracing interval along the vertical direction was taken as $0.4 \mathrm{~m}$. It has been decided to provide spring isolation. 


\section{Result and discussion}

It is known from Tables 2-3 that the natural time period of impulsive mode of filled tanks with the fixed base is highly deviated and is ranging from $3.0 \mathrm{~s}$ for tank 1 to $6.0 \mathrm{~s}$ for tank 4 , while the natural time period of the convective mode as well as that of empty tanks is fixed around 1.0 s. Natural time periods of base isolated tanks are also clearly depicted in Tables 2 and 3. Modal damping ratios of both filled as well as empty tanks with and without base isolation are graphically represented in Fig. 7. One can clearly see high damping ratios for 2nd and 3rd mode shapes compared to the fundamental mode. This high damping ratio is the main reason for very small seismic responses of higher modes.
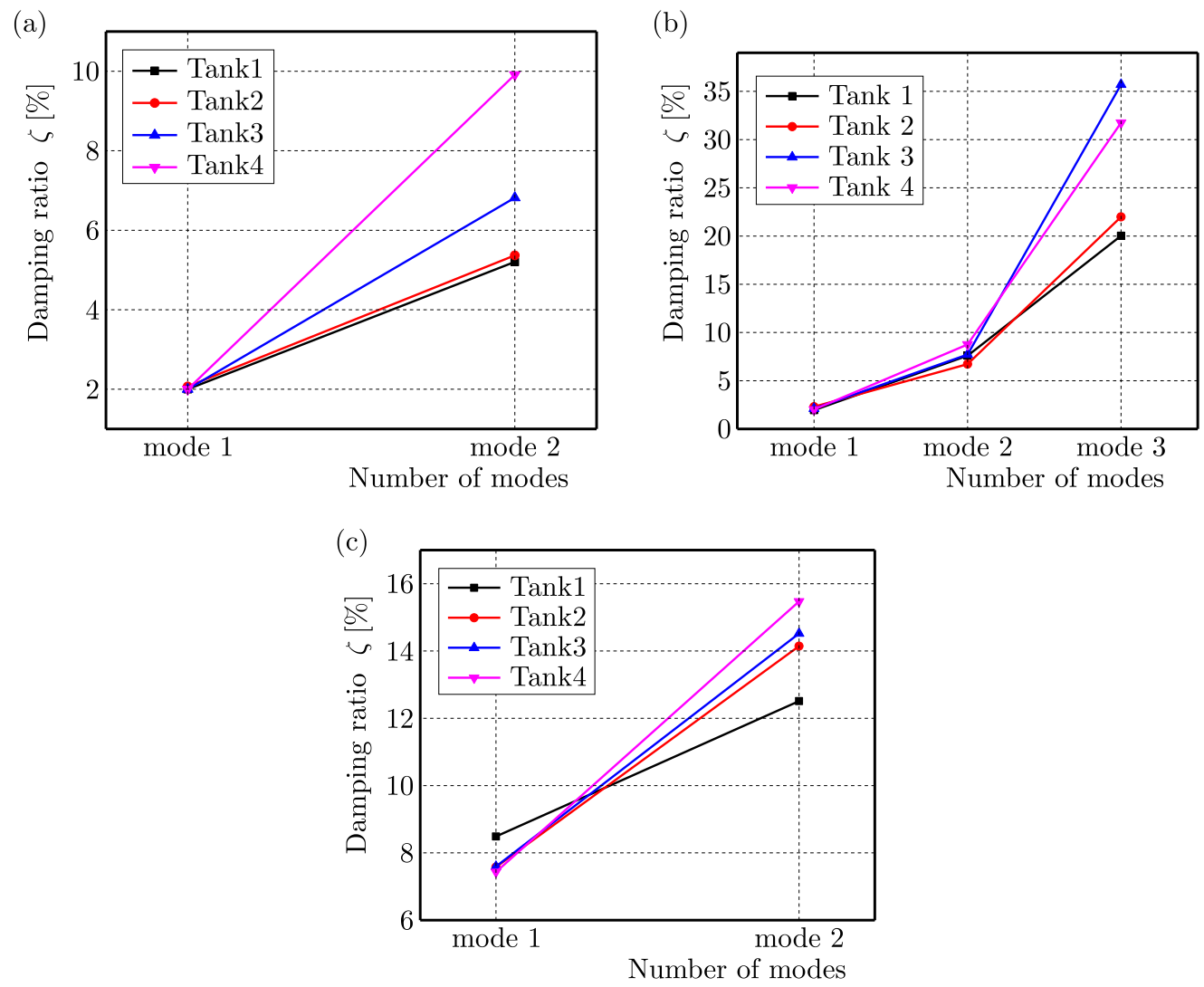

Fig. 7. Damping ratios of water tanks with different conditions: (a) filled tank without base isolation,

(b) filled tank with isolation, (c) empty tank with isolation

Spectral acceleration $S_{a} / g$, i.e., the dynamic response corresponding to any natural time period is obtained from the elastic design response spectrum available in (IS1893,(Part 1):2002) for damping ratio of $5 \%$. In the case of filled tanks with fixed base, ironically, the value of $S_{a} / g$ of the impulsive mode is smaller than that of the convective mode. As weight of the elevated water tank fully filled with water is highly lumped at the peak, its excitation during ground acceleration due to an earthquake resembles the 2nd mode, i.e., convective mode. Therefore, the contribution of the convective mode will always be higher than that of the fundamental, i.e., impulsive mode. It is delineated by significant reduction in the natural time period of the convective mode compared to that of the impulsive mode. For example, the natural time period of the first two modes of tank 4 ia $5.991 \mathrm{~s}$ and $1.209 \mathrm{~s}$, respectively. Similarly, the $S_{a} / g$ value for filled tanks with base isolation is going on increasing from the 1st to 3rd mode. But the huge amount of damping reduces the response contribution of the third mode and it is shown in Fig. 8. Similarly, $S_{a} / g$ values of empty tanks are also proportionate along with the natural time period and damping ratio. Static and dynamic responses of the base shear due to the fundamental mode 
(a)

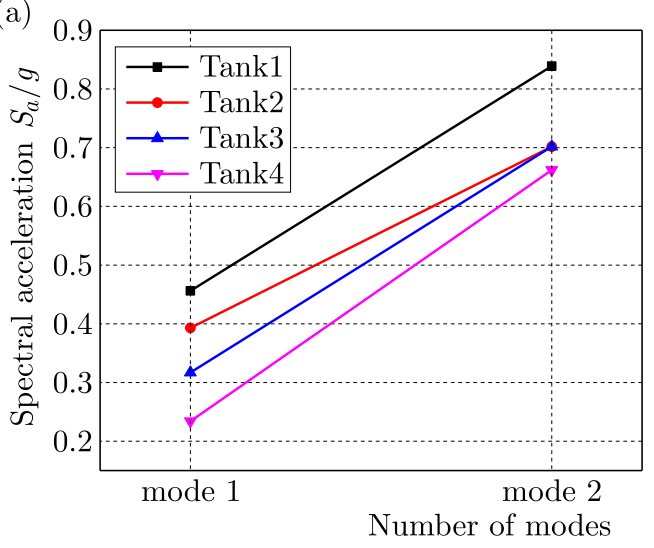

(b)

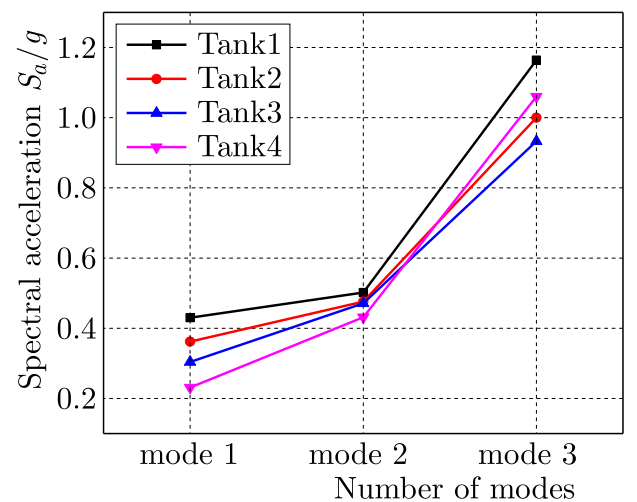

(c)

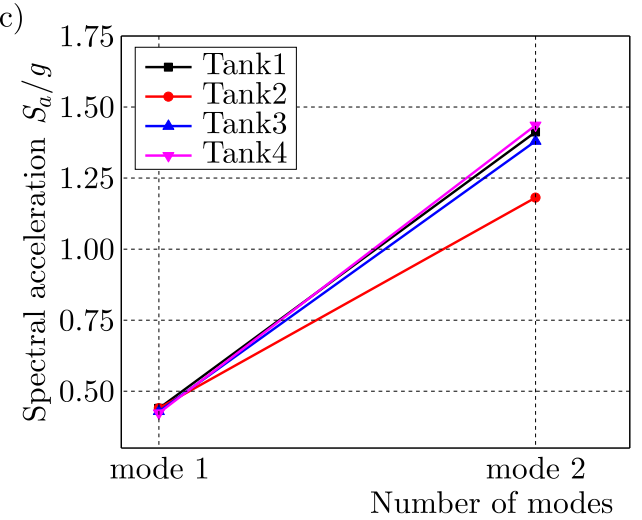

Fig. 8. Spectral acceleration coefficient of water tanks with different conditions (a) filled tank without base isolation, (b) filled tank with isolation, (c) empty tank with isolation

for filled tank 1 with the fixed base are 76.846 and 0.456 , respectively. The value of $Z I /(2 R)$ is calculated as 0.06 . Therefore, every spectral pseudo acceleration is to be multiplied by 0.06 in order to get the design horizontal seismic coefficient $A_{h}$. Multiplying these two gives the base shear response of $20.625 \mathrm{kN}$. Similarly, the second mode response is $58.362 \mathrm{kN}$. Finally, the total response due to the first and second mode has been obtained using the SRSS method and it is equal to $61.899 \mathrm{kN}$, i.e., $3.17 \%$ of the total weight $W$ of the tank. It is found out that the base shear induced from tank 1 to tank 4 is $3.17 \%, 3.3 \%, 3.36 \%$ and $4.69 \%$ of the total weight $W$ of the tanks filled with water, respectively. When it is provided with base isolation, the reduced values are $2.05 \%, 1.86 \%, 1.68 \%$ and $1.88 \%$ of $W$, respectively.

The base shear responses of all tanks with fixed base and isolated base have been calculated and they are tabulated, respectively, in Tables 5 and 6 .

Table 5. Response quantities of elevated water tanks with fixed base

\begin{tabular}{|c|c|c|c|c|c|c|c|c|c|c|c|c|}
\hline \multirow{3}{*}{ 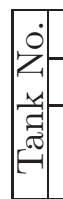 } & \multicolumn{9}{|c|}{ Tank filled with water } & \multirow{2}{*}{\multicolumn{3}{|c|}{ Empty tank }} \\
\hline & \multicolumn{3}{|c|}{ Impulsive mode } & \multicolumn{3}{|c|}{ Convective mode } & \multicolumn{3}{|c|}{ SRSS } & & & \\
\hline & \begin{tabular}{c|}
$V_{i}$ \\
{$[\mathrm{kN}]$}
\end{tabular} & $\begin{array}{c}M_{i} \\
{[\mathrm{kN} \mathrm{m}]}\end{array}$ & $\begin{array}{c}\left(\delta_{\text {roof }}\right)_{i} \\
{[\mathrm{~m}]}\end{array}$ & $\begin{array}{c}V_{c} \\
{[\mathrm{kN}]}\end{array}$ & $\begin{array}{c}M_{c} \\
{[\mathrm{kN} \mathrm{m}]}\end{array}$ & $\begin{array}{c}\left(\delta_{\text {roof }}\right)_{c} \\
{\left[10^{-3} \mathrm{~m}\right.}\end{array}$ & $\begin{array}{c}V \\
{[\mathrm{kN}]}\end{array}$ & $\begin{array}{c}M \\
{[\mathrm{kN} \mathrm{m}]}\end{array}$ & & $\begin{array}{c}V \\
{[\mathrm{kN}]}\end{array}$ & $\begin{array}{c}M \\
{[\mathrm{kN} \mathrm{m}]}\end{array}$ & $\begin{array}{c}\delta \\
{[\mathrm{m}]}\end{array}$ \\
\hline & 0.63 & & & .36 & & -0. & & 1023 & & & 126 & $\overline{\overline{0.02}}$ \\
\hline & .02 & & & 1. & 75 & -0 & & & & 8 & 2287.38 & .02 \\
\hline & प1 & 98.92 & & 79 . & & & & & & 59.35 & 4275.84 & 0 \\
\hline & (3) & 1016.24 & 0.131 & 027 & & -0.066 & 406. & & & & & \\
\hline
\end{tabular}


Table 6. Base shear $V[\mathrm{kN}]$ of elevated water tanks with base isolation

\begin{tabular}{|c|c|c|c|c|c|c|c|}
\hline \multirow{2}{*}{$\begin{array}{c}\text { Tank } \\
\text { No. }\end{array}$} & \multicolumn{4}{|c|}{ Tank filled with water } & \multicolumn{3}{c|}{ Empty tank } \\
\cline { 2 - 8 } & \begin{tabular}{c} 
Fundental \\
\cline { 2 - 8 }
\end{tabular} & 2nd mode & 3rd mode & SRSS & $\begin{array}{c}\text { Fundamental } \\
\text { mode }\end{array}$ & 2nd mode & SRSS \\
\hline \hline 1 & 29.701 & 25.904 & -7.206 & 40.064 & 26.470 & -6.405 & 27.234 \\
\hline 2 & 50.603 & 57.195 & -14.329 & 77.699 & 57.588 & -14.130 & 59.296 \\
\hline 3 & 73.568 & 107.04 & -9.431 & 130.226 & 96.686 & -19.777 & 98.688 \\
\hline 4 & 64.309 & 262.936 & -39.179 & 273.507 & 248.952 & -45.152 & 253.013 \\
\hline
\end{tabular}

Table 7. Base moment $M[\mathrm{kN} \mathrm{m}]$ of elevated water tanks with base isolation

\begin{tabular}{|c|c|c|c|c|c|c|c|}
\hline \multirow{2}{*}{$\begin{array}{c}\text { Tank } \\
\text { No. }\end{array}$} & $\begin{array}{c}\text { Fundamental } \\
\text { mode }\end{array}$ & 2nd mode & 3rd mode & SRSS & $\begin{array}{c}\text { Fundamental } \\
\text { mode }\end{array}$ & 2nd mode & SRSS \\
\cline { 2 - 8 } & $M_{1}$ & $M_{2}$ & $M_{3}$ & $M$ & $M_{1}$ & $M_{2}$ & $M$ \\
\hline \hline 1 & 526.36 & 411.79 & -118.21 & 678.68 & 434.85 & -105.23 & 447.40 \\
\hline 2 & 878.67 & 932.50 & -237.20 & 1303.03 & 953.94 & -234.07 & 982.24 \\
\hline 3 & 1282.53 & 1745.18 & -154.30 & 2171.25 & 1594.06 & -326.07 & 1627.07 \\
\hline 4 & 1143.43 & 4339.75 & -645.80 & 4534.09 & 4124.14 & -748.00 & 4191.42 \\
\hline
\end{tabular}

Table 7 shows that the contribution of the 2 nd mode is more significant than the fundamental mode. The prior reason behind this is the distribution of mass due to the fact that the impulsive and convective modes almost reflect the second natural mode. The base shear is increasing from tank 1 to tank 4 because the storage capacity of tank 4 is higher than that of other tanks. For example, the base shear of filled tank 4 with the fixed base is $406.710 \mathrm{kN}$, and when it is provided with base isolation it becomes reduced to $273.506 \mathrm{kN}$. The rate of reduction is $32.75 \%$. The rate of reduction is slightly above $30 \%$ for all filled tanks. Eventually, it is the empty tank with the fixed base, which carries the maximum base shear because of the shortest natural time period and lowest damping ratio. So, the empty tanks are highly vulnerable compared to all other types of tanks. Meanwhile, the rate of reduction calculated for empty tanks shows that it is around double times that of tanks filled with water, i.e., around $60 \%$. The reduction in the base shear is delineated in Figs. 9a and 9b. For example, the values of base shear of tank 4 for fixed and
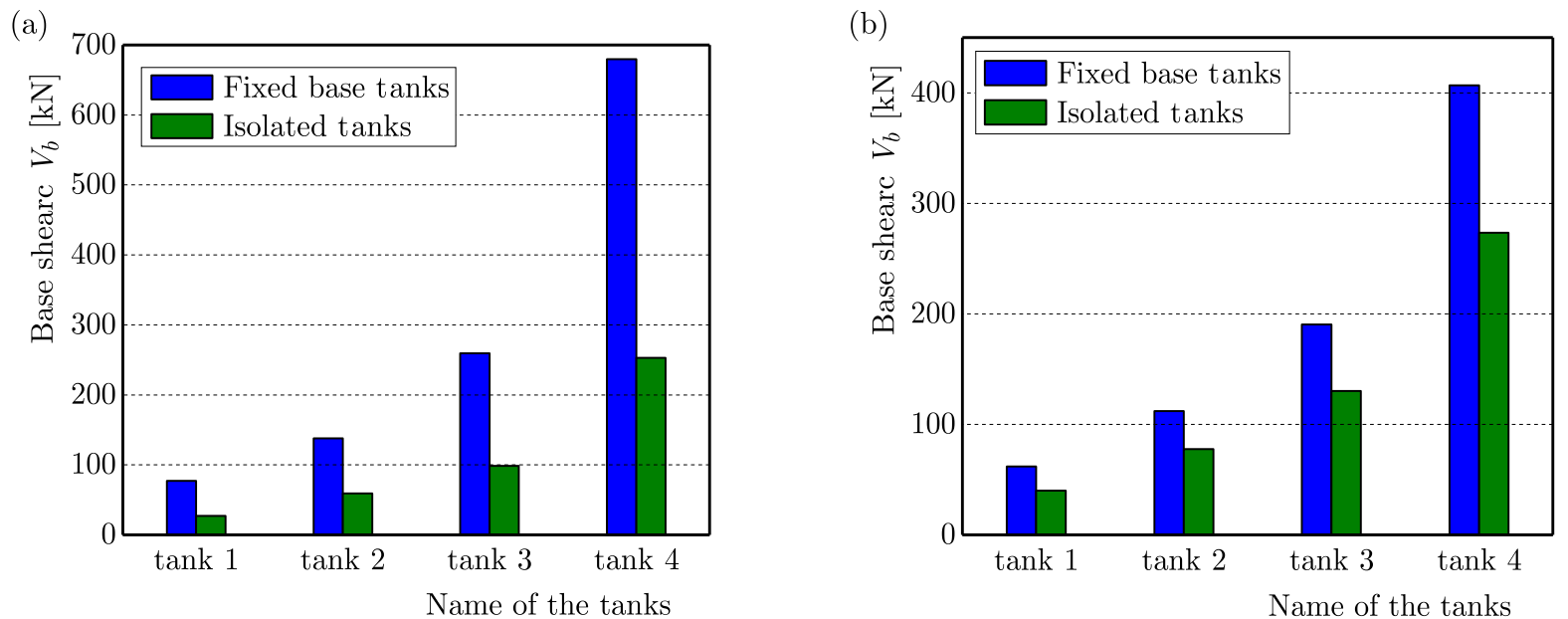

Fig. 9. Base shear of elevated water tanks with different conditions: (a) empty elevated water tank, (b) filled elevated water tank 
isolated based conditions are $679.891 \mathrm{kN}$ and $253.013 \mathrm{kN}$, respectively. Therefore, the percentage of reduction is $62.79 \%$. The base moment of empty tank 4 is very high, i.e., $11263.08 \mathrm{kN} \mathrm{m}$. It clearly shows that susceptibility of empty tanks can be significantly avoided by providing base isolation. The results of the base moment are shown in Table 7.

The variation of the base moment of all tanks with and without providing base isolation is depicted in Figs. 10a and 10b. Ironically, roof displacement of tanks with base isolation is higher than that of tanks with the fixed base.

(a)

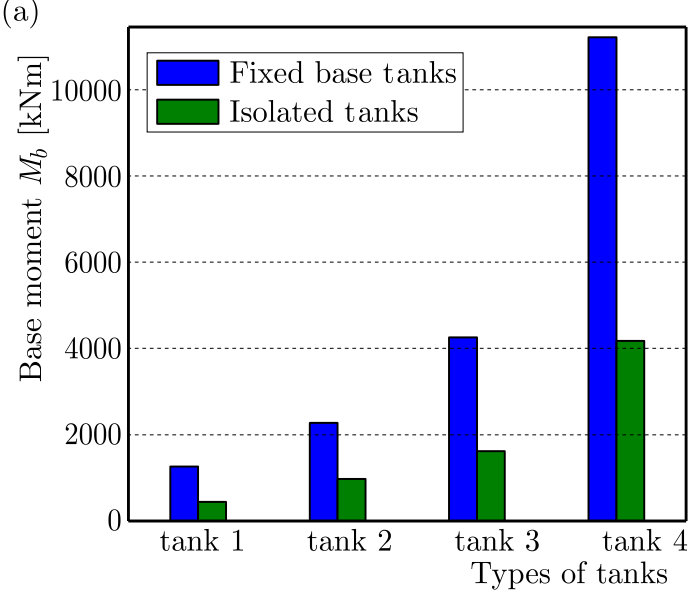

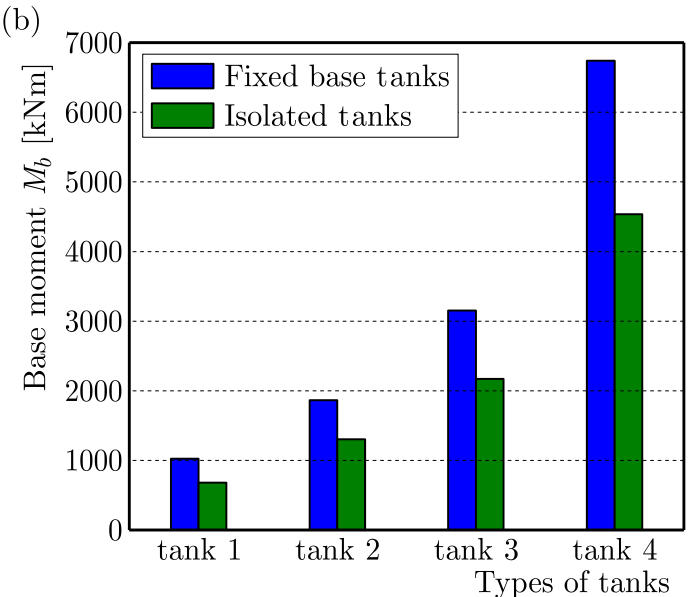

Fig. 10. Base moment of elevated water tanks with different conditions: (a) empty elevated water tank,

(b) filled elevated water tank

Figures 11a and 11b shows the $\delta_{\text {roof }}$ of both empty and filled tanks with and without base isolation. In the case of a filled tank, roof displacement is increased by around $11 \%$ for tanks 2,3 and 4 but it is $32.16 \%$ for tank 1 when they are provided with base isolation. Meanwhile, $\delta_{\text {roof }}$ of the empty tank is increased from $16 \%$ to $26 \%$ with the maximum displacement registered in tank 1 . For example, $\delta_{\text {roof }}$ of empty tank 1 with the fixed base is $21 \mathrm{~mm}$. When it is provided with base isolation, its value is increased to $26.52 \mathrm{~mm}$. But the isolator is displaced to the amount of $19.32 \mathrm{~mm}$. Therefore, the relative displacement of the roof with the base isolator is only $7.2 \mathrm{~mm}$. It is even less than $\delta_{\text {roof }}$ of an empty tank with the fixed base. But, in the case of a filled tank, the displacement of the isolator is very much smaller. As such, the relative displacement of the roof with respect to the isolator is not reduced considerably. The results of roof displacement of elevated tanks are shown in Table 8.
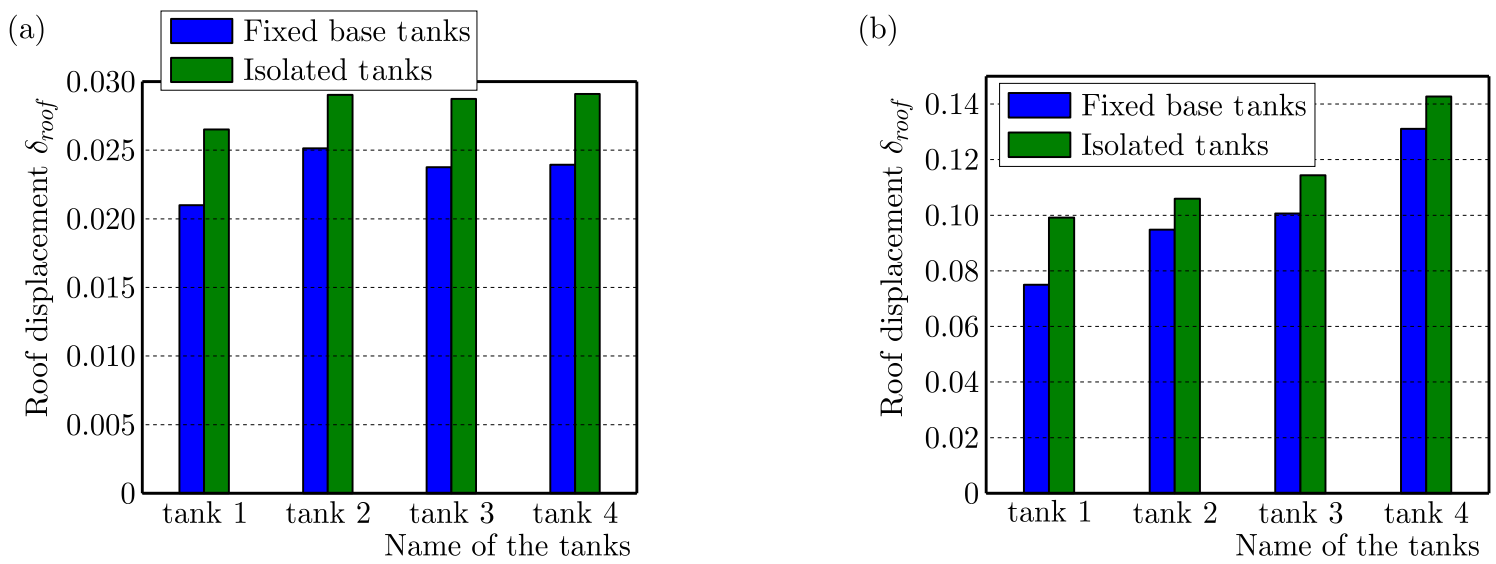

Fig. 11. Roof displacement of elevated water tanks with different conditions: (a) empty elevated water tank, (b) filled elevated water tank 
Table 8. Roof displacement $\delta_{\text {roof }}[\mathrm{m}]$ of elevated water tanks with base isolation

\begin{tabular}{|c|c|c|c|c|c|c|c|}
\hline \multirow{2}{*}{$\begin{array}{c}\text { Tank } \\
\text { No. }\end{array}$} & \multicolumn{4}{|c|}{ Tank filled with water } & \multicolumn{3}{c|}{ Empty tank } \\
\cline { 2 - 8 } & $\begin{array}{c}\text { Fundamental } \\
\text { mode }\end{array}$ & 2nd mode & 3rd mode & SRSS & $\begin{array}{c}\text { Fundamental } \\
\text { mode }\end{array}$ & 2nd mode & SRSS \\
\hline \hline 1 & $\left.\delta_{\text {roof }}\right)_{1}$ & $\left(\delta_{\text {roof }}\right)_{2}$ & $\begin{array}{c}\left(\delta_{\text {roof }}\right)_{3} \\
\times 10^{-3}\end{array}$ & $\delta_{\text {roof }}$ & $\left(\delta_{\text {roof }}\right)_{1}$ & $\left(\delta_{\text {roof }}\right)_{2}$ & $\delta_{\text {roof }}$ \\
\hline 2 & 0.09912 & -0.001032 & 0.0011268 & 0.09912 & 0.02652 & -0.000486 & 0.02652 \\
\hline 3 & 0.114548 & -0.010164 & 0.01014 & 0.10596 & 0.02904 & -0.00066 & 0.02904 \\
\hline 4 & 0.14268 & -0.005334 & 0.02196 & 0.11442 & 0.02874 & -0.000372 & 0.02874 \\
\hline
\end{tabular}

\section{Conclusion}

The following conclusions are made at the end of the response spectrum analysis of elevated water tanks provided with base isolation.

- The amount of base shear and base moment induced in elevated water tanks is directly proportional to its storage capacity. The contribution of the second mode in response quantities is more significant than that of the fundamental mode for both the tanks provided with and without base isolation.

- The most significant reason behind the reduction in base shear by base isolation is the lengthening of the fundamental natural time period beyond $0.4 \mathrm{~s}$, even though the presence of damping in the isolation system also reduces the base shear.

- Though the roof displacements of both empty and filled tanks with base isolation are higher compared to fixed tanks, their relative displacement with respect to the isolation device is very much less.

- Empty tanks are highly susceptible to earthquake damage because of their short fundamental natural time periods, if they are not provided with base isolation.

- It is concluded from the experimental results that the relative displacement of empty tanks is less than that of filled tanks.

- The rate of reduction of the maximum base shear for an empty tank is double to that of tanks filled with water. Therefore, it is concluded that the base isolation is highly effective for empty tanks.

\section{Acknowledgement}

The authors would like to express their sincere thanks to the civil engineering and structural engineering students of St. Xavier's Catholic College of Engineering, Kanyakumari, District, India, for their encouragement and support to the first author on the successful completion of this research work.

\section{References}

1. 3D Structural Analysis and Design Software STAAD.Pro, Bentley Sustaining Infrastructure

2. ACI American Concrete Institute: 350.3-06, 2006, Seismic Design of Liquid-Containing Concrete Structures, Farmington Hills, MI, USA

3. Agarwal P., Shrikhande M., 2013, Earthquake Resistant Design of Structures, PHI Learning Private Limited

4. Belostotskiy A.M., Akimov P.A., Afanasyeva I.N., Usmanov A.R., Scherbina S.V., VERSHININ V.V., 2015, Numerical simulation of oil tank behavior under seismic excitation. Fluid-structure interaction problem solution, Procedia Engineering, 111, 115-120 
5. Chaduvula U., Patel D., Gopalakrishnan N., 2013, Fluid-structure-soil interaction effects on seismic behavior of elevated water tanks, Procedia Engineering, 51, 84-91

6. Chopra A.K., 2012, Dynamics of Structures, 4th ed., Pearson Publication, California, USA

7. Clough R.W., Penzien J., 1993, Dynamics of Structures, 2nd ed., McGraw-Hill International Editions

8. Ghateh R., Kiaoush M.R., Pogorzelski W., 2015, Seismic response factors of reinforced concrete pedestal in elevated water tanks, Engineering Structures, 87, 32-46

9. Hirde S., Bajare A., Hedaoo M., 2011, Seismic performance of elevated water tanks, International Journal of Advanced Engineering Research and Studies, 1, 78-87

10. Housner G.W., 1963, Dynamic behavior of water tanks, Bulletin of the Seismological Society of America, 53, 381-387

11. IITK-GSDMA, 2007, Guidelines for Seismic Design of Liquid Storage Tanks, Kanpur, India, National Information Center of Earthquake Engineering

12. IS13920, 1993, Indian Standard Ductile Detailing of Reinforced Concrete Structures Subjected to Seismic Forces - Code of Practice, India

13. IS1893(Part 1), 2002, Indian Standard Criteria for Earthquake Resistant Design of Structures, Part 1, General Provisions and Building, (5th Revision), India

14. Kanyilmaz A., Castiglioni C.A., 2017, Reducing the seismic vulnerability of existing elevated silos by means of base isolation devices, Engineering Structures, 143, 477-497

15. LivaoĞLu R., DoĞAngün A., 2006, A simplified seismic analysis procedures for elevated tanks considering fluid-structure-soil interaction, Journal of Fluids and Structures, 22, 421-439

16. Mahadevan K., Reddy B.K., 2019, Design Data Handbook for Mechanical Engineers, 4th ed., CBS Publishers and Distributors Pvt Ltd.

17. Mirza Hessabi R., Mercan O., Ozturk B., 2017, Exploring the effects of tuned mass dampers on the seismic performance of structures with nonlinear base isolation systems, Eartquakes and Structures, 12, 3

18. Mori C., Sorace S., Terenzi G., 2015, Seismic assessment and retrofit of two heritage-listed R/C elevated water storage tanks, Soil Dynamics and Earthquake Engineering, 77, 123-136

19. NZS 3106, 2009, Design of Concrete Structures for the Storage of Liquids, Wellington, New Zealand, Standards Association of New Zealand

20. Paz M., Leigh W., 2010, Dynamics of Structures, Theory and Computation, 5th ed., Kluwer Academic Publishers

21. Seleemah A.A., El-Sharkawy M., 2011, Seismic response of base isolated liquid storage ground tanks, Ain Shams Engineering Journal, 2, 1, 33-42

22. Shekari M.R., Khaji N., Ahmadi M.T., 2010, On the seismic behavior of cylindrical base-isolated liquid storage tanks excited by long-period ground motions, Soil Dynamics and Earthquake Engineering, 30, 968-980

23. Shrimali M.K., JAngid R.S., 2004, Seismic analysis of base-isolated liquid storage tanks, Journal of Sound and Vibration, 275, 1-2, 59-75

24. Wang Y.-P., Teng M.-C., Chung K.-W., 2001, Seismic isolation of rigid cylindrical tanks using friction pendulum bearings, Earthquake Engineering and Structural Dynamics, 30, 7, 1083-1099 